\title{
Peguam Syarie di Malaysia: Analisis Perkembangan Pelaksanaannya di Mahkamah Syariah
}

\section{(Syariah Lawyers in Malaysia: Analysis on Its Implementation Process at the Syariah Courts)}

\author{
HAMMAD MOHAMAD DAHALAN \\ HJH MAS NOORAINI HJ MOHIDDIN \\ MOHAMAD RIZAL ABD RAHMAN \\ NUR KHALIDAH DAHLAN
}

\begin{abstract}
ABSTRAK
Peguam syarie mewakili pihak-pihak bertikai dalam menyelesaikan masalah mereka di mahkamah. Konsep perwakilan ini telah wujud sejak zaman Rasulullah sehingga kini. Kajian ini berhasrat untuk mencapai tiga objektif. Pertama, ianya menganalisis tadbir urus perwakilan peguam syarie pada zaman Rasulullah, sahabat serta pelaksanaannya di mahkamah syariah di Malaysia pada masa kini. Kedua, ianya mengenal pasti permasalahan semasa berkaitan tadbir urus tersebut di mahkamah syariah. Ketiga, ianya mencadangkan penyelesaian ke atas permasalahan yang dikenal pasti. Kajian ini mengguna pakai kerangka perundangan tulin yang dianalisis secara kualitatif. Data telah dikumpul melalui kaedah kajian perpustakaan serta kaedah temu bual separa struktur. Data perpustakaan kemudiannya dianalisis melalui kaedah-kaedah analisis kandungan dan analisis kritis. Data dari temubual pula dirakam, dilakukan transkripsi serta kemudiannya dimasukkan ke dalam penulisan sebagai hujah sokongan. Kajian mendapati tadbir urus perwakilan peguam syarie berkembang dari dari semasa ke semasa. Kajian turut mendapati ketidakseragaman dalam tadbir urus peguam syarie di mahkamah syariah pada masa kini. Kajian akhirnya mencadangkan agar diwujudkan tadbir urus peguam syarie yang seragam, teratur serta terperinci.
\end{abstract}

Kata kunci: Peguam syarie; mahkamah syariah; tadbir urus; perwakilan; prinsip syariah

\section{ABSTRACT}

Syariah lawyers represent adjudicating parties in solving their problems in court. The concept of representation existed eversince the time of the Prophet until now. This research aims to achieve three research objectives. Firstly, it analyses the governance of syariah lawyers' representation during the time of the Prophet, his companions and its implementation at the present Malaysian syariah courts. Secondly, it identifies current problems relating to its governance at the syariah courts. Thirdly, it suggests solutions to the identified problem. This research adopts the design of pure legal research that is being analysed qualitatively. The data are collected via library research as well as semi-structured interviews. These library data are then analysed via methods of content analysis and critical analysis. Data from interviews are recorded, transcribed, and incorporated in the writing as supporting analysis. This research finds that the governance of syariah lawyers' representation evolves from time to time. The research simultaneously identifies inconsistency in the governance of syariah lawyers at the present syariah courts. This research finally calls for a streamlined, regulated and refined governance of syariah lawyers.

Keywords: Syariah lawyers; sharia courts; governance; representation; shariah principles

\section{PENGENALAN}

Peguam syarie mewakili seseorang dalam sesuatu prosiding mahkamah serta berhak untuk bertindak dalam kes yang dipertikaikan sebagaimana diperuntukkan dalam kaedah-kaedah Peguam Syarie Negeri-Negeri. ${ }^{1}$ Peguam syarie juga dikhususkan sebagai individu yang telah dilantik oleh seseorang (yang merupakan pihak-pihak dalam prosiding) untuk membela serta mewakilinya dalam perbicaraan kes yang mahkamah mempunyai bidang kuasa. ${ }^{2}$ Seksyen 3 Enakmen Pentadbiran Agama Islam (Negeri Selangor) 2003 juga turut memberikan tafsiran "peguam syarie" sebagai peguam syarie yang dilantik di bawah seksyen 80 Enakmen Pentadbiran Agama Islam (Negeri Selangor) 2003.

Dari sudut fiqh pula, konsep wakalah bil alkhusumah dikaitkan dengan konsep perlantikan Peguam Syarie. Wakalah boleh didefinisikan sebagai pemeliharaan atau penyerahan atau perwakilan. Manakala khusumah bermaksud suatu dakwaan yang benar atau 
jawapan yang jelas dengan berkata "ya" atau "tidak." Konsep wakalah bil al-khusumah memberi pengertian perdebatan yang berlaku di antara dua pihak yang bertikai dan berbalah (Ain 2015: 35). Pensyariatan wakalah dalam setiap aspek kehidupan manusia termasuklah wakalah al-khusumah iaitu peguam telah disepakati oleh jumhur ulama. Perbicangan berkaitan wakalah telah dikupas secara khusus dalam bab-bab tertentu dalam kitab-kitab fiqh (Musa 2013: 15-16; Ain 2015: 35). Prinsip wakalah ini tidak ditolak oleh mana-mana mazhab dan ianya diterima pakai secara meluas di dalam pelbagai bidang terutamanya muamalat dan kepeguaman (Hafizal 2015; Musa 2013). Ayat 35 dalam surah al Nisa ini menjadi dalil kepada pengharusan pelantikan peguam syarie:

... maka lantiklah orang tengah (untuk mendamaikan mereka iaitu) seorang dari keluarga lelaki dan seorang dari keluarga perempuan...

Ayat ini menjelaskan keperluan wakil dalam membantu menyelesaikan dan mendamaikan masalah rumah tangga yang hubungannya sedang di ambang perpecahan. Pengharusan ini juga disebut dalam sebuah hadith Nabi sebagaimana berikut (Muhammad 2000: 181):

Dari Ibn Shihab dari Ubaidillah bin Abdullah, dari Zaid bin Khalid dan Abi Hurairah r.a dari Nabi SAw bersabda: Pergilah pagi-pagi wahai Unais kepada isteri orang ini. Apabila dia mengaku maka rejamlah.

Hadith ini menjelaskan Nabi SAW telah mewakilkan Unais untuk berjumpa dengan seorang perempuan dan sekiranya perempuan tersebut mengaku dengan kesalahannya maka perempuan tersebut akan dikenakan hukuman. Jelas di sini Unais merupakan wakil dan konsep perwakilan ini telah diguna pakai dalam menyelesaikan permasalahan yang ada pada zaman Nabi.

Islam mensyariatkan bahawa seseorang boleh menyerahkan urusannya kepada orang lain untuk menguruskannya, kerana tidak semua orang mampu menguruskan urusannya secara bersendirian. Dengan syarat, orang yang diwakilkan itu mestilah seorang yang layak, berkemampuan dan mempunyai pakar (Musa 2013). ${ }^{3}$

Keadilan yang wajib ditegakkan oleh umat Islam meliputi segala aspek dan bidang kehidupan. Berlaku adil dalam semua tindakan menjadi tuntutan Islam, tanpa mengira perbezaan bangsa, kebudayaan, warna kulit dan sebagainya. Implikasi daripada prinsip-prinsip tersebut, maka lahirlah institusi guaman di dalam Islam yang lebih dikenali sebagai Wakalah bi al-Khusumah (Musa 2013).

Berdasarkan surah al Maidah ayat 8 menyuruh manusia untuk berlaku adil kepada semua pihak sebagaimana berikut:

Hai orang-orang yang beriman, hendaklah kamu selalu berdiri karena Allah) menegakkan kebenaran-kebenaran-Nya (menjadi saksi dengan adil) (dan janganlah kamu terdorong oleh kebencian kepada sesuatu kaum) yakni kepada orangorang kafir (untuk berlaku tidak adil) hingga kamu menganiaya mereka karena permusuhan mereka itu. (Berlaku adillah kamu) baik terhadap lawan maupun terhadap kawan (karena hal itu) artinya keadilan itu (lebih dekat kepada ketakwaan. Dan bertakwalah kepada Allah, sesungguhnya Allah Maha Mengetahui apa yang kamu kerjakan) sehingga kamu akan menerima pembalasan daripadanya.

Ayat al-Quran ini menjelaskan peguam syarie perlu bertindak adil terhadap anak guam. Untuk itu, setiap tindakan Peguam Syarie tersebut perlu dikawal selia demi menjamin kepentingan peguam syarie serta pihak-pihak. Keadaan ini sejajar dengan kehendak sebuah hadith seperti berikut (Abu Tayyib 1979: 500):

Dari Ummu Salamah bahawa Nabi SAw bersabda: "Sesungguhnya aku adalah manusia dan kamu sekalian datang kepadaku membawa kes yang dipertelingkahkan (berselisih). Mungkin sebahagian kamu lebih pandai berhujah daripada yang lain, maka aku memutuskan sesuai dengan yang aku dengar, maka barangsiapa yang aku putuskan baginya sesuatu hak dari hak saudaranya hendaklah ia tidak mengambilnya kerana itu bererti saya memberikan kepadanya sepotong dari api neraka.

Hadith ini menunjukkan pengharusan untuk peguam syarie bersikap adil dalam setiap kes yang diwakilinya dan tidak menggunakan kepetahannya dalam berhujah untuk memenangi kes secara salah. Untuk itu, adalah amat wajar sekiranya Peguam Syarie ini dikawal selia pelantikan dan tindakannya supaya dapat menjamin kepentingan Peguam Syarie dan pihak-pihak. Dalam situasi ini, kaedah fiqh ada menyebut (Jalil 2013: 3-5):

Pemerintah menguruskan rakyatnya berdasarkan kemaslahatan.

Berdasarkan kaedah fiqh ini jelas menuntut supaya pihak berkuasa yang bertanggungjawab mengambil tindakan membuat pindaan ke atas peruntukan undangundang tertentu untuk mengawal selia tadbir urus peguam syarie. Usaha untuk meminda dan menambah baik peruntukan undang-undang ini selari dengan kehendak syariah adalah menepati prinsip siyasah al syariyyah yang mementingkan kemaslahatan masyarakat dalam pemerintahan (Jalil 2013: 3-5). Undang-undang yang mantap, jelas, teratur dan sistematik membantu masyarakat untuk menjalani kehidupan seharian dengan lebih baik serta sempurna. Dengan ini, martabat profesion guaman syarie dapat dipertingkatkan serta menepati kehendak prinsip syariah. Di Malaysia, pelantikan serta tadbir urus berkaitan peguam syarie dikawal selia di bawah Kaedah-kaedah Peguam Syarie di setiap negeri di Malaysia (Zulkifli, Hasnizam 2017: 5).

Secara umumnya, perwakilan Peguam Syarie ini telah diamalkan sejak zaman Nabi dan para sahabat sehingga kini. Pada zaman Nabi dan para sahabat, tadbir urusnya dikawal selia berdasarkan prinsip syariah. Kehadiran Peguam Syarie di Mahkamah Syariah hari ini bukanlah suatu perkara yang enteng atau remeh, kerana mereka menjalankan tugas atau peranan yang pernah 
dijalankan oleh sahabat-sahabat Nabi SAW (Musa 2013). Amalan perlantikan dan tadbir urus peguam syarie di mahkamah syariah di Malaysia dikukuhkan serta diperhalusi lagi selaras dengan keadaan isu semasa yang wujud serta perkembangan sistem perundangan syariah pada masa kini dengan penggubalan undangundang berkaitan tadbir urus Peguam Syarie di bawah Kaedah-kaedah Peguam Syarie di setiap negeri. Rang Undang-undang Profesion Peguam Syarie Wilayah Persekutuan 2019 hangat diperkatakan pada masa kini berhubung pelaksanaannya yang dilihat dapat menjadi perundangan berkaitan tadbir urus Peguam Syarie yang lebih jelas dan teratur. Kajian ini seterusnya akan membincangkan berkaitan perkembangan tadbir urus peguam syarie pada zaman Nabi, sahabat dan masa kini serta mencadangkan penambahbaikan yang perlu diambil dalam memperkasakan profesion Peguam Syarie di Malaysia.

\section{METODOLOGI}

Kajian ini merupakan kajian perundangan tulen. Kajian ini mengguna pakai kaedah kajian kualitatif yang bercirikan doktrinal. Kesemua data kajian berkaitan perkembangan tadbir urus Peguam Syarie pada zaman Nabi, sahabat dan masa kini dikumpul melalui kaedah kajian perpustakaan. Maklumat-maklumat ini yang dikumpul melalui buku-buku, jurnal-jurnal, kes-kes syariah dan peruntukan undang-undang berkaitan tadbir urus peguam syarie dianalisis dengan menggunakan metod analisis kandungan dan analisis kritis. Kajian ini turut menganalisis data kajian dengan menggunakan kaedah tema dengan penyusunan bahan secara tema dalam penyusunan isi mengikut isu-isu tertentu. Dalam masa yang sama, pengkaji turut menggunakan kaedah deskriptif ke atas data kajian yang diperolehi. Kaedah kajian temu bual juga diguna pakai untuk mendapatkan data kajian. Untuk itu, kajian ini telah menemu bual ketua hakim syarie di setiap negeri. Informan-informan yang ditemu bual merupakan individu yang mempunyai pengalaman luas berkaitan tadbir urus Peguam Syarie di Malaysia. Pengkaji menggunakan kaedah transkripsi ke atas data temu bual dengan menulis rakaman yang dilakukan. Hasil temu bual tersebut digunakan untuk menyokong dapatan kajian pengkaji.

\section{PERKEMBANGAN PELAKSANAAN TADBIR URUS PEGUAM SYARIE PADA ZAMAN RASULULLAH DAN SAHABAT}

Pelaksanaan perwakilan Peguam Syarie di zaman Rasulullah SAW dapat dilihat melalui hadith daripada Jabir Bin Abdullah r.a., beliau berkata (Musa 2013: 15-17):

Suatu ketika aku berhajat untuk keluar ke Khaibar, lalu aku pergi berjumpa baginda Rasulullah SAW. Aku menceritakan tentang hajatku untuk ke Khaibar, lalu baginda SAw bersabda, jika kamu berjumpa wakilku, maka ambillah daripadanya lima belas gantang (gandum) dan jika dia meminta daripadamu bukti (bahawa engkau adalah wakilku) maka letakkanlah tanganmu ke atas bahu sebagai bukti.

Dalam hadith ini jelas menunjukkan konsep perwakilan telah diamalkan oleh Rasulullah SAW dalam urusan sehariannya. Dalam pada itu, pelaksanaannya turut dapat dilihat dalam peristiwa bayaran zakat, baginda SAW pernah mengutus al-Su'at r.a. untuk mengutip zakat. Baginda SAW juga telah mewakilkan 'Amru bin Umayyah al-Damiri r.a. dalam menikahkan Ummu Habibah bin Abu Sufyan r.a. Rasulullah SAW juga mewakilkan Abu Rafi'i r.a. untuk menerima pernikahan Maimunah Binti al-Harith. Seterusnya Rasulullah SAW pernah melantik 'Urwah al-Bariqi r.a. untuk membeli seekor kibas (Musa 2013: 15-16). Peristiwa-peristiwa ini menggambarkan bahawa konsep perwakilan sudah menjadi amalan seharian. Sekiranya diperhatikan, individu-individu yang dilantik Rasulullah SAW sebagai wakil adalah para sahabat yang mempunyai pengetahuan tentang perkara berkenaan.

Konsep perwakilan ini berterusan sehingga ke zaman para sahabat. Hal ini dapat disaksikan dalam peristiwa yang berlaku di zaman Khalifah Umar Al-Khattab r.a. pada tahun kebuluran. Pada ketika ini, seorang wanita yang sedang menghadapi kebuluran telah meminta dirinya dikenakan hukuman rejam oleh Khalifah Umar. Wanita ini mendakwa dirinya telah melakukan zina dan mengandung. Saidina Ali telah memainkan peranan sebagai wakil untuk membela wanita tersebut. Dalam penelitian kes tersebut, Saidina Ali mendapati bahawa wanita tersebut telah dirogol. Penzinaan yang berlaku bukan merupakan kerelaan diri wanita itu. Wanita itu terpaksa melakukan zina demi menyelamatkan dirinya yang sedang kebuluran. Wanita ini telah ditawarkan oleh pasangan zinanya susu sekiranya wanita itu menyerahkan mahkota diri kepada pasangan zinanya. Saidina Ali r.a. dengan jelas memainkan peranannya sebagai seorang wakil untuk membela wanita tersebut yang akhirnya dibebaskan daripada hukuman atas alasan darurat. Peristiwa ini jelas menunjukkan kepentingan seorang wakil yang boleh menghalang daripada berlakunya hukuman yang tidak adil pada pihak yang teraniaya (Musa 2013: 15-16).

Dalam peristiwa yang lain, konsep perwakilan peguam syarie ini dapat disaksikan pada zaman Khalifah Umar r.a., peristiwa ini menyaksikan Saidina Ali telah memainkan peranannya sebagai wakil dan membela seorang lelaki yang difitnah dari dikenakan hukuman atas kesalahan yang beliau tidak pernah dibuat. Fitnah ini terjadi apabila seorang wanita telah datang mengadu kepada Khalifah Umar r.a. dan mendakwa bahawa lelaki tersebut telah merogolnya. Wanita tersebut mengemukakan bukti yang berupa cecair putih yang ada pada kainnya (yang didakwa sebagai air mani lelaki tersebut). Lelaki tersebut menafikan dakwaan 
wanita ini dan beliau menyatakan bahawa dirinya telah diperangkap dan beliau menegaskan penafiannya dengan sumpah. Setelah mendengar pembelaan lelaki tersebut, Saidina Umar r.a meminta pendapat Saidina Ali berkaitan kes ini. Setelah dianalisis kes ini, Saidina Ali bahawa cecair yang ada pada kain wanita tersebut bukanlah air mani tetapi ia merupakan putih telur apabila putih telur tersebut timbul setelah dicurahkan air panas ke atasnya. Akhirnya wanita tersebut mengaku setelah disiasat bahawa dia telah menipu dan memerangkap lelaki ini kerana dendam setelah lamarannya ditolak (Musa 2013: 15-16).

Di zaman pemerintahan Uthman bin Affan, Ali bin Abi Talib dan Talhah bin Ubaidullah pernah melantik Abdullah bin Ja'far menjadi peguam (Musa 2017). Konsep pelantikan peguam syarie semasa zaman Khalifah Uthman juga dapat disakiskan dalam satu peristiwa yang lain apabila Abdullah bin Abbas dilantik menjadi peguam kepada Hassan bin Thabit. Hassan bin Thabit dan beberapa orang yang lain telah terlibat dalam satu pertikaian dan kes ini dibawa ke hadapan Saidina Uthman. Sebagai penghakiman, Saidina Uthman telah mengenakan hukuman ke atas Hassan. Hassan merasakan dirinya tidak bersalah dan pergi mengadu kepada Abdullah bin Abbas untuk mewakili dirinya merayu ke atas penghakiman yang dibuat oleh Saidina Uthman. Ibnu Abbas bersama Hassan berjumpa dengan Uthman dan mengeluarkan hujah-hujah pembelaan bagi pihak Hassan (Zafir 1978: 261). Peristiwa ini jelas menunjukkan konsep perwakilan membenarkan seseorang itu melantik wakil walaupun dalam membantu mereka merayu terhadap sesuatu keputusan penghakiman. Seperkara yang perlu diambil kira dalam peristiwa ini adalah kepakaran Ibnu Abbas dalam berhujah menyebabkan beliau dipilih untuk membela Hassan, walaupun Hassan seorang penyair tetapi dia tidak mahir berhujah dalam perbicaraan. Dengan ini, peristiwa-peristiwa di atas jelas menunjukkan konsep perwakilan ini diterima semasa zaman sahabat. Para sahabat memainkan peranan sebagai wakil (peguam syarie) dalam membantu menyelesaikan masalah masyarakat. Dalam masa yang sama, peristiwa-peristiwa ini juga menunjukkan bahawa perwakilan melalui seseorang yang pakar dapat membantu hakim mengeluarkan penghakiman yang memihak kepada yang berhak serta menacapai keadilan mengikut kehendak syarak.

Dr Abdullah (1997) dalam kajiannya telah membuat kesimpulan bahawa profesion guaman sudah pun dikenali di negara Arab dan negara Islam yang lain selepas terjalinnya hubungan dengan negara Barat, bukan selepas penaklukannya. Mahkamah Syariah di Mesir sebelum tahun 1845 merupakan satu-satunya mahkamah yang tersusun yang mempunyai banyak bidang kuasa yang memutuskan suatu pertikaian.

Kajian mendapati peranan peguam syarie telah wujud sejak zaman Nabi SAW dan para sahabat untuk membantu pihak-pihak dalam mencapai keadilan. Konsep perwakilan ini adalah berdasarkan prinsip syariah berkaitan keadilan. Untuk itu, dalam mencapai keadilan, para sahabat telah melantik seseorang yang pakar untuk mewakili mereka dan berhujah dalam menyelesaikan kes secara adil. Seperkara yang perlu diberi perhatian, pelaksanaan tadbir urus peguam syarie pada zaman Nabi dan sahabat tidak diaplikasikan secara khusus melalui perundangan dan badan tertentu, sebaliknya ianya ditadbir secara persendirian dan menepati prinsip keadilan.

\section{PERKEMBANGAN TADBIR URUS PEGUAM \\ SYARIE DI MAHKAMAH SYARIAH: ANALISIS PERMASALAHAN DAN DAPATAN KAJIAN}

Konsep perwakilan di zaman Nabi dan sahabat berkembang sehingga ke masa kini. Jika diperhatikan, di Malaysia, tadbir urus peguam syarie adalah di bawah bidang kuasa negeri sepertimana yang diperuntukkan di bawah Senarai II Jadual Sembilan Perlembagaan Persekutuan. Kesannya, pentadbiran berkaitan peguam syarie dilihat tidak seragam dan berbeza antara negerinegeri. Ini bermakna setiap prosedur yang berkaitan tadbir urus peguam syarie adalah bergantung kepada penetapan di bawah undang-undang yang berkaitan di setiap negeri.

Di Malaysia, Majjalah Al-Ahkam Johor 1331H telah menggubal undang-undang berkaitan profesion guaman syarie. Menurut undang-undang tersebut, pihak yang mendakwa dan pihak yang didakwa berhak untuk diwakili dengan sesiapa yang mereka pilih. Undangundang tersebut membenarkan sesiapa sahaja untuk menjadi wakil kepada mana-mana pihak dengan syarat wakil tersebut dapat menjalankan tugas perwakilan dengan baik terutamanya bagi yang mahir dalam prosiding yang berjalan di mahkamah (Abu Bakar 2000:77). Dalam masa yang sama, memiliki kelulusan undang-undang juga menjadi faktor utama yang dilihat untuk melayakkan seseorang menjadi peguam syarie (Zawawi 2003: 109-133).

Peranan utama wakil adalah berkisar dalam ruang lingkup prosiding perbicaraan. Wakil bertindak sebagai perantara yang menyuarakan hak anak guam, dan pada masa yang sama bertindak sebagai pembantu Mahkamah dari segi prosiding dan fakta kes, suasana dan latar belakang kes serta latar belakang pihak yang bertikai, supaya keadilan dapat ditegakkan dengan sebenarbenarnya. Tugas wakil atau peguam lebih besar dari seorang pegawai Mahkamah (Musa 2013).

Sebelum Merdeka, Undang-undang Pentadbiran Agama Islam telah membenarkan seseorang untuk hadir di mahkamah sebagai Peguam Syarie di mahkamah. Ini jelas menunjukkan amalan Peguam Syarie telah wujud semasa zaman sebelum merdeka. Walau bagaimanapun, undang-undang tersebut membenarkan kehadiran 
peguam di mahkamah dalam prosedur mal sahaja. Sekeyen 51 Enakmen Hukum Syarak (Selangor) 1952 memperuntukkan hal berkaitan kehadiran, iaitu di dalam hal berkaitan jenayah pihak terlibat hadir perlu hadir manakala di dalam prosedur mal, pihak-pihak perlu hadir sendiri bersama wakil. Undang-undang Pentadbiran Agama Islam Negeri Sembilan No.3, Tahun 1952. Seksyen 50 (1) undang-undang ini memperuntukkan bahawa:

Dengan tidak menghiraukan apa-apa yang tersebut dalam mana-mana undang-undang, seseorang peguam itu tidak berhak untuk mengambil bahagian dalam satu-satu perbicaraan yang bertentangan dengan undang-undang Islam.

Dalam masa yang sama, peruntukan ini turut mengiktiraf kehadiran Peguam Syarie di dalam mahkamah syariah. Kehadiran Peguam Syarie pada zaman belum merdeka turut boleh disaksikan dalam kes Ramah lwn Laton (1927 6 FMSLR). Dalam kes ini, mahkamah mengeluarkan penghakiman bahawa undangundang syariah hendaklah dianggap sebagai "land of law" dan pada masa yang sama ianya menunjukkan amalan guaman syarie telah ada walaupun bukan dalam bentuk yang rasmi dan tersusun (Zulkifli 2017: 5). Sungguhpun begitu, pada masa ini, wakil-wakil ini dinamakan sebagai pembantu atau penolong bicara, tiada nama "peguam syarie" yang khusus seperti mana pada hari ini (Musa 2013: 15-16).

Dalam memperkasakan dan memberi tambah baik berkaitan tadbir urus Peguam Syarie, Jawatankuasa Tun Syed Nasir telah ditubuhkan pada tahun 1972 untuk melakukan kajian berkaitan kedudukan peguam syarie dan laporan jawatankuasa tersebut dihantar kepada Majlis Kebangsaan. Laporan tersebut telah dikaji semula pada tahun 1982 oleh satu jawatankuasa yang baharu. Pada tahun 1983, jawatankuasa ini kemudiannya mencadangkan agar Peguam Syarie yang dilantik ini perlulah menguasai dan memahami dengan baik hukum syarak kerana pentas perbicaraan mereka adalah mahkamah syariah yang mengendalikan kes-kes berkaitan hukum syarak. Untuk memperkukuhkan lagi cadangan tersebut, turut dicadangkan agar peguampeguam syarie ini diwajibkan memiliki kelulusan syariah. Dalam pada itu, jawatankuasa ini turut mencadangkan agar satu peruntukan undang-undang diwujudkan untuk membenarkan peguam syarie ini beramal di mahkamah syariah. Ini kerana menurut Ketua Hakim Syarie, Mahkamah Tinggi Syariah Brunei, peguam syarie bukan sekadar satu profesion bahkan beban dan tanggungjawab sebenarnya adalah berat, ia bukan sahaja memerlukan kefahaman dan iltizam yang mendalam bahkan ia memerlukan ilmu yang mantap, kefahaman diri yang jitu serta pegangan yang jelas dalam isu-isu hukum syarak mahupun perundangan (Aimi 2018).

Seterusnya, undang-undang tersebut dibuat penambahbaikan yang lebih baik. Gelaran "peguam syarie" telah dimasukkan secara khusus di dalam Seksyen
51 Enakmen Pentadbiran Agama Islam (Perak) 1965 (Enakmen No.11 Tahun 1965) yang membenarkan kehadiran Peguam Syarie mewakili mana-mana pihak di mahkamah. Seksyen tersebut berbunyi:

1. Peguam syarie boleh-lah mengambil bahagian dalam mana-mana mahkamah bagi satu pihak dalam perbicaraan.

2. Majlis hendaklah menyediakan daftar nama pada tiap-tiap tahun bagi orang-orang yang didapati layak dan berkemahiran dalam hukum Shara' supaya boleh menjadi pembela dalam mahkamah yang ditubuhkan di bawah undang-undang ini. Orang-orang itu dikenali sebagai Peguam Shari'ah.

3. Peguam Syarie tidak boleh hadir dalam mana-mana mahkamah bagi mana-mana pihak dalam satusatu perbicaraan melainkan dengan lesen bertulis yang dikeluarkan oleh Majlis dengan menjelaskan bayaran yang ditetapkan. Lesen yang demikian hendaklah dikeluarkan tiap-tiap tahun dan ditanda tangani oleh Yang di-Pertua.

Perubahan dan penambahbaikan dilakukan dari masa ke semasa ke atas undang-undang berkaitan tadbir urus Peguam Syarie yang menjadikannya lebih tersusun, sistematik serta positif. Seterusnya, undangundang negeri telah mensyaratkan kepada keperluan tauliah bertulis untuk melayakkan seseorang itu beramal sebagai Peguam Syarie di mahkmah syariah negerinegeri. Untuk itu, syarat-syarat yang melayakkan seseorang diterima masuk sebagai peguam syarie juga ditambah baik mengikut negeri-negeri. Contohnya di dalam seksyen 8 (1) Enakmen Pentadbiran Perundangan Islam 1989 Selangor (undang-undang ini menggantikan Undang-undang Agama Islam Negeri Selangor 1952 yang memperuntukkan berkaitan kehadiaran peguam syarie), seksyen tersebut memperuntukkan bahawa seseorang peguam syarie antaranya hendaklah seseorang yang berkelulusan Ijazah Sarjana Muda Syariah yang diiktiraf oleh Majlis, mendapat latihan profesional yang diiktiraf oleh Majlis dalam bidang kehakiman Islam.

Seksyen 80 Enakmen Pentadbiran Agama Islam (Negeri Sembilan) 2003 memperuntukkan Majlis diberi kuasa untuk membuat Kaedah-kaedah Peguam Syarie bagi negeri masing-masing. Antara kaedah-kaedah yang digubal ialah Kaedah-kaedah Peguam Syarie (Kelantan) 1988, Kaedah-kaedah Peguam Syarie (Pahang) 1990, Kaedah-kaedah Peguam Syarie (Melaka) 1989 dan sebagainya. Kaedah-kaedah yang ada ini juga turut dipinda dari semasa ke semasa. Contohnya yang terkini bagi Kedah ialah Peraturan-peraturan Peguam Syarie (Kedah Darul Aman) 2016.

Walau bagaimanapun, undang-undang tersebut dikawal selia di bawah bidang kuasa agama Islam di setiap negeri dan menjadikan undang-undang ini dilihat tidak selaras dan tidak seragam antara negeri-negeri. Ketidakselarasan ini akhirnya telah menyebabkan berlakunya kekeliruan kepada pengamal undangundang syariah dan masyarakat. Berdasarkan jadual 
di bawah menunjukkan wujudnya ketidakseragaman dalam jawatankuasa peguam syarie di negeri-negeri di Malaysia.

Melalui Jadual 1.0, jelas wujud ketidakseragaman dalam setiap negeri di bawah Kaedah-kaedah dan Peraturan-peraturan Peguam Syarie. Jika diperhatikan, jawatan pengerusi dalam jawatankuasa telah disandang oleh jawatan yang berbeza-beza seperti yang telah ditetapkan dalam Kaedah-Kaedah atau PeraturanPeraturan Peguam Syarie mengikut negeri masingmasing. Secara umumnya, Ketua Hakim Syarie akan bertindak sebagai Pengerusi Jawatankuasa, kecuali bagi Jawatankuasa dalam Negeri Johor yang dipengerusikan oleh Penasihat Undang-Undang. Seterusnya, Negeri

JADUAL 1 Nama dan keanggotaan jawatankuasa Peguam Syarie Negeri-Negeri

\begin{tabular}{|c|c|c|c|}
\hline Negeri & Pengerusi & Ahli Tetap & Ahli Dilantik \\
\hline Selangor & $\begin{array}{l}\text { Ketua } \\
\text { Hakim Syarie }\end{array}$ & $\begin{array}{l}\text { - Penasihat Undang-Undang Negeri/Wakil } \\
\text { - Seorang Hakim Mahkamah Rayuan Syariah } \\
\text { Jabatan Kehakiman Syariah Malaysia } \\
\text { - Seorang Hakim Kanan Mahkamah Tinggi Syariah } \\
\text { - Ketua Pendakwa Syarie }\end{array}$ & $\begin{array}{l}\text { - Seorang Peguam Syarie } \\
\text { - Seorang Yang Berkemahiran Hukum } \\
\text { Syarak }\end{array}$ \\
\hline $\begin{array}{l}\text { Wilayah } \\
\text { Persekutuan }\end{array}$ & $\begin{array}{l}\text { Ketua } \\
\text { Hakim Syarie }\end{array}$ & $\begin{array}{l}\text { - Peguam Negara/ Wakil } \\
\text { - Ketua Pendakwa Syarie }\end{array}$ & 2 Orang Dilantik Oleh Majlis \\
\hline Kedah & $\begin{array}{l}\text { Ketua } \\
\text { Hakim Syarie }\end{array}$ & $\begin{array}{l}\text { - Penasihat Undang-Undang Negeri } \\
\text { - Setiausaha Majlis } \\
\text { - Ketua Pendaftar Jabatan Kehakiman Syariah Negeri } \\
\text { - Ketua Pendakwa Syarie }\end{array}$ & $\begin{array}{l}\text { - Seorang Wakil Peguam Syarie } \\
\text { - Seorang Yang Arif Dalam Hukum } \\
\text { Syarak }\end{array}$ \\
\hline Terengganu & $\begin{array}{l}\text { Yang Dipertua } \\
\text { Majlis Agama } \\
\text { Islam Dan } \\
\text { Adat Melayu } \\
\text { Terengganu }\end{array}$ & $\begin{array}{l}\text { - Penasihat Undang-Undang Negeri/Wakil } \\
\text { - Mufti } \\
\text { - Ketua Hakim Syarie } \\
\text { - Ketua Pendakwa Syarie }\end{array}$ & $\mathrm{X}$ \\
\hline Johor & $\begin{array}{l}\text { Penasihat } \\
\text { Undang-Undang } \\
\text { Negeri }\end{array}$ & $\begin{array}{l}\text { - Ketua Pegawai Eksekutif MAIJ } \\
\text { - Mufti Atau Wakil } \\
\text { - Ketua Hakim Syarie } \\
\text { - Ketua Pendakwa Syarie }\end{array}$ & Wakil PGSM \\
\hline $\begin{array}{l}\text { Negeri } \\
\text { Sembilan }\end{array}$ & $\begin{array}{l}\text { Ketua } \\
\text { Hakim Syarie }\end{array}$ & $\begin{array}{l}\text { - Penasihat Undang-Undang Negeri/Wakil } \\
\text { - Hakim Mahkamah Rayuan Syariah } \\
\text { - Hakim Kanan Mahkamah Timggi Syariah } \\
\text { - Ketua Pendakwa Syarie } \\
\text { - Wakil Peguam Syarie } \\
\text { - Seorang Berkemahiran Hukum Syarak }\end{array}$ & $\begin{array}{l}\text { - Penasihat Undang-Undang Negeri/Wakil } \\
\text { - Hakim Mahkamah Rayuan Syariah } \\
\text { - Hakim Kanan Mahkamah Tinggi Syariah } \\
\text { - Ketua Pendakwa Syarie }\end{array}$ \\
\hline Perak & $\begin{array}{l}\text { Ketua } \\
\text { Hakim Syarie }\end{array}$ & $\begin{array}{l}\text { - Mufti/ Wakil } \\
\text { - Penasihat Undang-Undang Negeri/ Wakil } \\
\text { - Ketua Bahagian Undang-Undang Syariah, JAIP }\end{array}$ & $\begin{array}{l}\text { Seorang Peguam Syarie Atas Syor Ketua } \\
\text { Hakim Syarie }\end{array}$ \\
\hline Kelantan & $\begin{array}{l}\text { Ketua } \\
\text { Hakim Syarie }\end{array}$ & - Pendakwa Syarie & 3 Orang Dilantik Sultan \\
\hline $\begin{array}{l}\text { Pulau } \\
\text { Pinang }\end{array}$ & Ahli Majlis & $\begin{array}{l}\text { - Ketua Pendakwa Syarie } \\
\text { - Penasihat Undang-Undang Negeri/ Wakil }\end{array}$ & 2 Orang Berkemahiran Hukum Syarak \\
\hline Perlis & $\begin{array}{l}\text { Pengerusi } \\
\text { Dilantik }\end{array}$ & $\begin{array}{l}\text { - Pendakwa Syarie } \\
\text { - } 2 \text { Orang Ahli Majlis Berkemahiran Hukum Syarak }\end{array}$ & $\begin{array}{l}\text { - Seorang Wakil Peguam Syarie } \\
\text { oleh Majlis }\end{array}$ \\
\hline Pahang & Pengerusi & $\begin{array}{l}\text { - Penasihat Undang-Undang Negeri } \\
\text { - Ketua Pendakwa Syarie }\end{array}$ & 2 Orang Dilantik Majlis \\
\hline Sarawak & $\begin{array}{l}\text { Hakim } \\
\text { Mahkamah } \\
\text { Tinggi Syariah }\end{array}$ & $\begin{array}{l}\text { - Ketua Pendakwa Syarie } \\
\text { - Pendaftar Mahkamah Tinggi Syariah }\end{array}$ & $\begin{array}{l}\text { - Seorang Peguam Syarie Yang Dilantik } \\
\text { oleh Ketua Hakim Syarie } \\
\text { - } 2 \text { Orang Ahli Lain Berkemahiran } \\
\text { Kehakiman Islam/ Hukum Syarak }\end{array}$ \\
\hline Melaka & $\mathrm{X}$ & $\mathrm{X}$ & $\mathrm{X}$ \\
\hline Sabah & $\mathrm{X}$ & $\mathrm{X}$ & $\mathrm{X}$ \\
\hline
\end{tabular}

Sumber: Kaedah-kaedah Peguam Syarie di Negeri-negeri di Malaysia 
Pahang pula tidak menetapkan jawatan tertentu untuk menyandang sebagai Pengerusi Jawatankuasa. Selain itu, bagi Negeri Perlis pula, Pengerusi hendaklah dilantik oleh Majlis. Seterusnya, di Pulau Pinang pula, Pengerusi bagi Jawatankuasa hendaklah dilantik seorang daripada kalangan Ahli Majlis. Selain itu, berbeza pula di Negeri Sarawak kerana Hakim Mahkamah Tinggi Syariah yang akan bertindak sebagai Pengerusi Jawatankuasa. Akhir sekali, bagi Negeri Terengganu pula, Yang Di-Pertua Majlis Agama Islam dan Adat Melayu Terengganu yang akan bertindak sebagai Pengerusi Jawatankuasa.

Dalam masa yang sama, berdasarkan Jadual 1 tersebut, ahli lain dalam jawatankuasa Peguam Syarie juga tidak seragam sepertimana yang ditetapkan oleh negeri Negeri Johor, Kedah, Negeri Sembilan, Pahang, Perak, Pulau Pinang, Selangor dan Terengganu yang menjadikan Penasihat Undang-Undang Negeri atau wakilnya sebagai anggota dalam Jawatankuasa Peguam Syarie masing-masing. Manakala di Wilayah Persekutuan pula telah menetapkan Peguam Negara atau wakilnya akan berada dalam jawatankuasa tersebut. Namun, tiada peruntukan berhubung Penasihat UndangUndang Negeri atau wakilnya sebagai anggota dalam Jawatankuasa Peguam Syarie di Kelantan, Melaka, Perlis, dan Sarawak.

Dalam pada itu, jika diperhatikan dari sudut syarat kelayakan peguam syarie juga wujud ketidakseragaman terutamanya jika dilihat dari sudut kelayakan akademik. Kaedah-kaedah Peguam Syarie di Negeri Selangor, Negeri Sembilan dan Perak mensyaratkan pemohon memiliki Ijazah Sarjana Muda Syariah dari mana-mana Universiti atau mana-mana institusi pengajian tinggi yang diiktiraf oleh Kerajaan Malaysia serta memiliki Diploma Undang-undang Pentadbiran Kehakiman Islam daripada Universiti Islam Antarabangsa atau mana-mana Diploma Lepasan Ijazah yang setaraf dan diiktiraf oleh kerajaan Malaysia. Manakala Kaedah-kaedah Peguam Syarie di negeri-negeri lain tidak mensyaratkan kelayakan pemohon untuk memiliki Diploma Lepasan Ijazah, pemohon disyaratkan memiliki Ijazah Sarjana Muda Syariah sahaja. Malah Kaedah-kaedah Peguam Syarie di ketiga-tiga negeri tersebut juga mensyaratkan kelayakan tamat latihan dalam kamar di mana-mana firma guaman syarie dan syarat ini tidak dinyatakan dalam mana-mana peruntukan Kaedah-kaedah Peguam Syarie di negeri-negeri lain.

Dalam konteks tatatertib, Jabatan Kehakiman Syariah Malaysia (JKSM) telah mengeluarkan Arahan Amalan No 4 Tahun 2002 berkaitan Etika Peguam Syarie sebagai garis panduan khusus terhadap kesalahan yang boleh dikenakan tatatertib menurut Kaedah Peguam Syarie Negeri. Sungguhpun begitu, senarai kesalahan dalam Kaedah Peguam Syarie tidak dihuraikan secara meluas. Untuk itu, Kod etika peguam syarie JKSM ini akan digunakan untuk menghurai lebih mendalam kesalahan yang diadukan. Ini bermakna Majlis Agama Islam Negeri boleh menerima aduan serta mengambil tindakan tatatertib ke atas kesalahan yang diperuntukkan dalam Kaedah Peguam Syarie Negeri sahaja. Seterusnya, sebagai contoh perbandingan, kajian ini mengemukakan bentuk kesalahan yang boleh dikenakan tindakan tatatertib di negeri Selangor dan di Wilayah Persekutuan. Subkaedah 17(2) Kaedah Peguam Syarie Negeri Selangor 2008, terdapat 16 kesalahan yang boleh dikenakan tindakan tatatertib oleh Jawatankuasa Peguam Syarie Selangor. Dalam pada itu, subkaedah 17 (2) Kaedah-kaedah Peguam Syarie Wilayah Persekutuan 1993, hanya terdapat 8 peruntukan kesalahan yang boleh dikenakan tindakan tatatertib peguam syarie. Kajian mengemukakan perbezaan kedua-dua peruntukan undang-undang tersebut melalui Jadual 2.0 seperti berikut:

JADUAL 2 Bentuk kesalahan yang boleh dikenakan tindakan tatatertib di bawah kaedah-kaedah Peguam Syarie Negeri Selangor dan Wilayah Persekutuan

Subkaedah 17(2) Kaedah Peguam Syarie Negeri Selangor 2008

(1) Majlis boleh, atas sebab yang wajar, mengenakan tindakan tatatertib ke atas mana-mana Peguam Syarie mengikut peruntukan bahagian ini.

(2) Sebab yang wajar itu boleh ditunjukkan dengan membuktikan bahawa Peguam Syarie itu -

(a) telah berkelakuan mengikut apa-apa cara yang bertentangan dengan Hukum Syarak;

(b) telah membuat apa-apa pernyataan awam sama ada secara lisan atau bertulis yang semunasabahnya boleh ditafsirkan sebagai menghina agama Islam atau Majlis;

(c) telah disabitkan oleh mana-mana Mahkamah di Malaysia atau di mana-mana negara lain atas apa-apa kesalahan jenayah di bawah mana-mana undang-undang bertulis;
Subkaedah 17 (2) Kaedah-kaedah Peguam Syarie Wilayah Persekutuan 1993

(a) telah disabitkan atas suatu kesalahan jenayah;

(b) telah melakukan kesalahan pecah amanah dalam melakukan tugas-tugas profesionalnya atau kelakuan fraud ataukelakuan selainnya yang tak sesuai dengan seseorang Peguam Syarie;

(c) telah memberikan menjanjikan atau menawarkan manamana orang sama dan bagi faedah orang itu atau orang lain, apa-apa suapan sebagai suatu dorongan kepada atau hadiah bagi mendapatkan pekerjaan dalam apa-apa urusan perundangan bagi dirinya sendiri atau mana-mana Peguam Syarie lain; 
(d) telah dengan sengaja atau tanpa apa-apa sebab yang munasabah enggan menjalankan kewajipannya terhadap kliennya;

(e) telah melanggar tanggungjawabnya kepada Mahkamah yang termasuk apa-apa kegagalannya untuk mematuhi akujanji yang diberikannya kepada mahkamah;

(f) telah melakukan dengan perbuatan atau perkataan atau dengan apa-apa cara yang boleh semunasabahnya ditafsirkan sebagai menghina mahkamah;

(g) mengenakan fi atau kos yang melampau mengikut semua hal keadaan, dalam ketiadaan apa-apa persetujuan bertulis, berhubung dengan perkhidmatan profesional yang diberikan kepada kliennya;

(h) tidak jujur atau bertingkah laku secara fraud dalam melaksanakan tugasnya;

(i) telah menawarkan atau memberi atau bersetuju memberi suapan kepada mana-mana orang kerana telah mendapatkan pekerjaan bagi dirinya atau mana-mana Peguam Syarie lain dalam apa-apa urusan undang-undang;

(j) telah secara langsung atau secara tidak langsung mendapatkan atau cuba mendapatkan pekerjaan bagi dirinya atau bagi seseorang Peguam Syarie lain melalui atau dengan arahan seseorang yang kepadanya sesuatu saraan kerana mendapatkan pekerjaan itu telah diberi olehnya atau dipersetujui untuk diberi sedemikian;

(k) telah menerima pekerjaan dalam apa-apa urusan perundangan melalui seorang penarik langganan;

(1) membenarkan mana-mana orang yang bukan seorang Peguam Syarie mengusahakan atau menjalankan urusan perundangan atas namanya atau firmanya tanpa orang itu berada di bawah kawalannya;

(m) menjalankan dengan sendiri atau melalui mana-mana orang lain yang diguna khidmat olehnya apa-apa tred, perniagaan atau kerjaya yang pada pendapat Majlis adalah tidak sesuai dengan kedudukannya sebagai Peguam Syarie;

(n) telah didapati bersalah oleh Lembaga Disiplin yang ditubuhkan di bawah subseksyen 93(1) Akta Profesion Undang-undang 1976;

(o) telah diisytiharkan sebagai bankrap dan belum dilepaskan; atau

(p) telah melanggar atau mungkir mematuhi mana-mana peruntukan Kaedah ini atau mana-mana undang-undang bertulis, jika pada pendapat Majlis pelanggaran atau kemungkiran itu memerlukan tindakan tatatertib. (d) telah secara langsung atau tak langsung mendapatkan atau cuba mendapatkan pekerjaan bagi dirinya sendiri atau mana-mana Peguam Syarie lain melalui atau dengan arahan mana-mana orang yang kepadanya apa-apa saraan bagi mendapatkan pekerjaan itu telah diberikan olehnya atau dipersetujui atau dijanjikan untuk diberikan sedemikian;

(e) telah menerima pekerjaan dalam apa-apa urusan perundangan melalui seseorang penarik langganan;

(f) membenarkan mana-mana kerani atau mana-mana orang lain yang tak diberikuasa untuk mengusahakan atau menjalankan urusan perundangan atas namanya sedangkan kerani atau orang lain yang tak diberi kuasa itu tidak berada di bawah kawalan prinsipalnya bagi memastikan dia tidak bertindak tanpa pengawasan yang sepatutnya;

(g) menjalankan dengan sendiri atau melalui mana-mana orang yang bekerja dengannya apa-apa tred, perniagaan atau kerjaya yang pada pendapat Jawatankuasa adalah tidak sesuai dengan kedudukannya sebagai Peguam Syarie;

(h) telah melanggar atau tidak mematuhi mana-mana peruntukan Kaedah-Kaedah ini atau mana-mana kaedahkaedah lain yang dibuat di bawah Akta jika pada pendapat Jawatankuasa pelanggaran atau kemungkiran itu memerlukan tindakan tatatertib.

Sumber: Subkaedah 17(2) Kaedah Peguam Syarie Negeri Selangor 2008 dan Subkaedah 17 (2) Kaedah-kaedah Peguam Syarie Wilayah Persekutuan 1993

Jika diperhatikan, Kaedah-kaedah Peguam Syarie Wilayah Persekutuan 1993 memperuntukkan kesalahan-kesalahan terlalu umum dan ringkas serta tidak merangkumi kesalahan-kesalahan lain yang diperuntukkan dalam Kaedah-kaaedah Peguam Syarie Negeri Selangor 2008. Jika keadaan ini sedemikian, mana-mana kesalahan yang diadukan adalah tidak diperuntukan di bawah Subkaedah 17(2), Kaedahkaedah Peguam Syarie Wilayah Persekutuan 1993, aduan tersebut tidak boleh diambil tindakan selanjutnya kerana tidak wujud asas untuk melakukan tindakan menurut undang-undang (Zalikhah 2001: 143)
Seterusnya, wujud kekaburan dalam pengaplikasian prosedur tatatertib. Ini dapat dilihat sebagaimana dilaporkan dalam berita mengenai kes Muhamad Burok (M.Mageswari 2012). Dalam laporan berita ini menyatakan bahawa Muhamad Burok telah gagal menghadiri satu keputusan cerai di mahkamah. Akibatnya, Muhamad Burok telah dikenakan tindakan penggantungan tugas sebagai Peguam Syarie di Mahkamah Syariah Wilayah Persekutuan selama enam (6) bulan bermula 1 Jun 2012. Permohonan semakan telah dibuat dan Mahkamah Tinggi Shah Alam mengisytiharkan keputusan kedua-dua responden 
tersebut adalah tidak sah serta melangkaui bidang kuasa. Mahkamah membatalkan keputusan keduakedua responden. Melalui laporan berita kes tersebut, kajian mendapati terdapat kekaburan dalam Kaedahkaedah Peguam Syarie berkaitan prosedur tatatertib dan menyebabkan keputusan mahkamah adalah tidak sah terhadap peguam syarie apabila peruntukan undangundang yang mengawal selia tatatertib peguam syarie tersebut diputuskan telah melangkaui bidang kuasa.

Dalam pada itu, Jabatan Kehakiman Syariah Malaysia telah ditubuhkan pada tahun 1998 sebagai salah satu usaha dalam menyeragamkan undang-undang berkaitan permasalahan ketidakseragaman yang wujud di Mahkamah Syariah dengan mengeluarkan Arahan Amalan No.4 Tahun 2002 berkaitan etika peguam syarie (Mazni 2016: 175-178). Walaupun telah wujud Arahan Amalan sebagai salah satu usaha penyeragaman di setiap negeri, namun perlu diakui bahawa masih wujud kelompangan serta ketidakseragaman tadbir urus peguam syarie yang berlaku. Antara perkara yang paling jelas adalah berkaitan dengan ahli jawatankuasa peguam syarie, syarat-syarat perlantikan peguam syarie dan tatatertib peguam syarie di negeri-negeri. Berdasarkan temubual bersama Dato' Sri Haji Abdul Rahman bin Md Yunos (Ketua Hakim Syarie Pahang), Dato' Abu Bakar Abdullah Kutty (Hakim Kanan Mahkamah Tinggi Syariah Kota Bharu, Kelantan), Datuk Jasri@Nasip bin Mat Jakir (Ketua Hakim Syarie Sabah) dan Tuan Muhammad Adib bin Husain (Ketua Hakim Syarie Selangor), informan-informan menyokong dapatan kajian ini bahawa wujudnya ketidakseragaman dan kekaburan dalam tadbir urus jawatankuasa peguam syarie, syarat kelayakan peguam syarie serta prosiding tatatertib peguam syarie tersebut. Ketidakseragaman dan kekaburan ini akhirnya boleh membawa kepada pengaplikasiannya yang tidak berkesan, tidak jelas dan tidak teratur dan seterusnya mengakibatkan kesan negatif dalam urusan tadbir peguam syarie di Malaysia ${ }^{4}$ (Rahman; Abu Bakar; Jasri; Adib 2019).

Sehingga masa kini, usaha penyeragaman dan penambahbaikan masih lagi diteruskan. Antara usaha yang terbaru dilakukan melalui penggubalan Rang Undang-undang (RUU) Profesion Guaman Syarie (Wilayah-wilayah Persekutuan). RUU tersebut telah mendapat perkenan Yang di-Pertuan Agong. Perkara ini dilihat sebagai salah satu langkah yang baik ke arah penyeragaman undang-undang berkaitan tadbir urus peguam syarie. RUU ini boleh dijadikan model bagi menggalakkan keseragaman pentadbiran agama negeri melalui proses rundingan. RUU ini juga dilihat telah meminda dan menambahbaik tadbir urus peguam syarie yang diperuntukan dalam Kaedah-kaedah Peguam Syarie berkaitan jawatankuasa peguam syarie, syarat kelayakkan peguam syarie dan prosedur tatatertib peguam syarie menjadi lebih teratur, jelas dan sistematik. Sungguhpun RUU ini telah digubal, ianya masih lagi tidak menangani permasalahan yang wujud. Masih lagi berlaku ketidakseragaman tadbir urus Peguam Syarie di setiap negeri berikutan bidang kuasa berkaitan hal tadbir urus Peguam Syarie ini terletak di bawah bidang kuasa negeri. Namun, usaha yang baik ini harus diberikan pujian dan penghargaan kerana satu bentuk model tadbir urus Peguam Syarie yang baik telah dibina. Ianya boleh menjadi contoh kepada negeri-negeri lain untuk mengendroskan perundangan seperti ini di negeri lain. Dalam pada masa yang sama, pada hemat pengkaji, RUU ini mencedok Akta Profesion Guaman Sivil 1976 dan menjadikan ianya sebagai model dalam menggubal RUU ini. Sekiranya RUU ini diwartakan sebagai undang-undang, pengkaji merasakan perlu adanya penambah baikkan dilakukan ke atas RUU ini. Hal ini kerana, undang-undang di mahkamah syariah adalah bersifat tidak mengikat dan mana-mana alasan penghakiman berkaitan tadbir urus Peguam Syarie tidak mengikat pengamal undang-undang syariah untuk mematuhinya. Jika sedemikian, perkara ini perlu dititikberatkan dan diambil perhatian dalam usaha menjadikan RUU ini lebih terperinci, jelas, teratur serta sistematik supaya tidak timbul sebarang pertikaian mengenainya dikemudian hari.

Secara ringkasnya, kajian mendapati bahawa konsep perwakilan ini telah diamalkan sejak zaman Nabi SAW dan para sahabat. Amat jelas bahawa konsep perwakilan ini berdasarkan prinsip syariah berkaitan keadilan. Kajian mendapati usaha menggubal, meminda, menambah baik dan penyeragaman undangundang berkaitan tadbir urus peguam syarie ini adalah menepati kaedah fiqh yang menyokong tindakan pihak berkuasa dalam menyediakan apa-apa jua bentuk kemaslahatan kepada masyarakat. Sudah pasti usahausaha seperti ini adalah menepati kehendak kaedah fiqh ini dan ianya bermatlamatkan menjaga maqasid syariah . Sebagaimana konsep perwakilan Peguam Syarie yang dianjurkan oleh Nabi dan para sahabat yang sentiasa mementingkan keadilan serta memberikan maslahah kepada masyarakat, sudah tentu perkembangan peguam syarie di Malaysia dilihat sebagai langkah memartabatkan syariat Islam dalam bidang ini. Walau bagaimanapun kewujudan Arahan Amalan dan pelbagai usaha penyeragaman dan penambahbaikan yang dibuat masih lagi belum mencukupi untuk menangani masalah ketidakseragaman serta wujud kelompangan dalam peruntukan undang-undang tersebut. Hal ini kerana pelaksanaan undang-undang Islam di Malaysia mengikut ketetapan negeri-negeri dan sifatnya tidak mengikat. Oleh yang demikian, pengkaji menghujahkan bahawa masih lagi wujud kelompangan dalam peruntukan undang-undang berkaitan tadbir urus Peguam Syarie.

\section{KESIMPULAN}

Sebagai kesimpulan, kajian ini telah membincangkan mengenai konsep perwakilan peguam syarie pada 
zaman Nabi dan para sahabat. Kajian ini juga telah membincangkan secara umum prinsip syariah berkaitan keadilan yang diterapkan dalam konsep perwakilan Peguam Syarie ini. Kajian seterusnya mendapati bahawa tiada sebarang tadbir urus Peguam Syarie yang khusus wujud pada zaman Nabi dan para sahabat. Oleh kerana pembangunan sistem undang-undang syariah telah mendesak keperluan penambahbaikan dilakukan kepada tadbir urus peguam syarie agar pelaksanaannya seiring dengan perkembangan zaman. Pelbagai usaha untuk penambahbaikan telah dilakukan dan suatu peruntukan undang-undang khusus berkaitan peguam syarie diwujudkan. Namun oleh kerana ianya diwujudkan di bawah bidang kuasa negeri-negeri di Malaysia, maka berlaku ketidakselarasan pelaksanaannya.

Untuk itu sebagai cadangan, pertamanya, pengkaji mencadangkan agar Rang Undang-undang (RUU) Profesion Guaman Syarie (Wilayah-wilayah Persekutuan) ini dijadikan model utama kepada setiap negeri di Malaysia dalam usaha mengtadbir urus peguam syarie. Adalah amat diharapkan sekiranya setiap negeri dapat mengaplikasikan mekanisma undang-undang seperti RUU ini dan seterusnya dapat menjadikan tadbir urus peguam syarie adalah seragam di seluruh Malaysia. Kedua, pengkaji mencadangkan agar usaha penambahbaikan turut dibuat ke atas RUU serta Kaedah dan Peraturan Peguam Syarie sedia ada di setiap negeri. Pindaan ini dibuat untuk menjadikannya sesuai dengan sifat undangundang Islam di Malaysia yang bersifat tidak mengikat. Untuk itu, adalah amat wajar sekiranya perincianperincian dibuat terhadap pengaplikasian tadbir urus peguam syarie agar ianya menjadi lebih teratur, terurus, jelas dan lebih sistematik. Adalah turut menjadi harapan agar setiap cadangan pindaan yang dilakukan tersebut itu perlulah menepati prinsip keadilan yang telah diterapkan dalam konsep perwakilan dalam Islam.

Pengkaji turut memuji usaha-usaha untuk penyelerasan dan penambahbaikan yang telah dibuat dari masa ke semasa. Kesemua usaha ini yang berasaskan kepada prinsip syariah berkaitan keadilan menjadi langkah yang amat penting dalam memastikan tadbir urus Peguam Syarie lebih positif. Keadaan ini sudah pastinya mengalakkan sebarang kajian lanjut dilakukan oleh para penyelidik, pengamal undang-undang syariah dan ahli akademik dalam bidang yang berkenaan untuk mengembangkan serta memperincikan lagi peruntukan undang-undang berkaitan tadbir urus Peguam Syarie di Malaysia. Adalah amat pening untuk masyarakat pada masa kini mengetahui bahawa usaha-usaha positif ini termasuklah kajian pengkaji ini perlu diperkembangkan dan diperhalusi lagi dalam memberikan aura positif ke atas tadbir urus peguam syarie pada satu masa nanti.

\section{NOTA}

Mahmud Saedon A. Othman. Institusi Pentadbiran Undang-undang dan Kehakiman Islam, Dewan Bahasa dan Pustaka, Kuala Lumpur, 1996, p123.
2 Temu bual bersama Datuk Jasri@Nasip bin Mat Jakir, Ketua Hakim Syarie Sabah di Kota Kinabalu Sabah. 13 Mac 2019.

3 Musa, Awang. Peranan Peguam Syarie di Dalam Sistem Pentadbiran Kehakiman Islam di Malaysia: Sejarah, Cabaran dan Halatuju. Seminar Amalan Guaman Syarie 2013, 26 Oktober 2013. Klana Beach Resort Port Dickson.

4 Temu bual bersama Datuk Jasri@Nasip bin Mat Jakir, Ketua Hakim Syarie Sabah di Kota Kinabalu Sabah. 13 Mac 2019.

\section{RUJUKAN}

Abdul Aziz bin Amir. 1969. Al-Ta'zir fi al-Syariah al-Islamiah. Kaherah: Dar al-Fikr al-Arabi.

Abdul Aziz Mohamed Azzam. 2005. Al-Qawaid al-Fiqhiyyah. Kaherah: Dar al-Hadis.

Abdul Jalil Borham. 2013. Konsep Siyasah Syar'iyyahdan Pelaksanaannya dalam Konteks Malaysia. https://www. academia.edu/14310539/Konsep_Siyasah_Syariyyah dan_Pelaksanaannya [21 Oktober 2019]

Abdul Munir bin Yaakob. 2002. Pembangunan Undang-undang di Rantau Asean. Kuala Lumpur: Institut Kefahaman Islam Malaysia.

Abdul Wahhab Khallaf. 1978. 'Ilm Ushul al-Fiqh. Kuwait: Dar al-Qalam.

Abdullah Abu Bakar. 2000. Guaman Syarie: Antara Teori Dan Praktikal dalam Al-Ahkam Penghakiman dan Kepeguaman. Kuala Lumpur. Dewan Bahasa dan Pustaka.

Abdullah Abu Bakar. 1997. Guaman Syarie:Antara Teori dan Praktikal. Kuala Lumpur. Dewan Bahasa dan Pustaka,

Abu Tayyib Muhammed Shams al-Haq. 1979. 'Awn al-Ma'bul. Bab fi Qada’ al-Qadi Iza Akhtaa. Hlm. 500.

Abu Tayyib Muhammed Shams al-Haq. 1979. 'Awn al-Ma'bul. Jilid 9. Beirut: Dar' al-Fikr.

Aimi Saini. 2018. Tanggungjawab Peguam Syarie Bukan Sekadar Profesion. Pelita Brunei. 8 March 2018. Brunei Darussalam: Jabatan Penerangan.

Al-Imam al-Allamah Burhanuddin Abi al-Wafa' Ibrahim. Tabsirah al-Ahkam. Dar al-Kutub al-Ilmiah.

Al-Samnani, 'Ali bin Muhammad Al-Rahbi Al-Samnani. 1984. Raudzah al-Qudzah wa Tariq al-Najah. Jilid 1. Beirut: Muassasah al-Risalah.

Bernama. 2011. Hukuman Tatatertib Terhadap Tujuh Peguam Syarie Kekal. https://www.mstar.com.my/lokal/ semasa/2011/10/10/hukuman-tatatertib-terhadap-tujuhpeguam-syarie-kekal/ [10 Oktober 2019]

Ibn Farhun, Burhanuddin Abu al-Wafa' Ibrahim bin Syamsuddin. 1995. Tabsirah al-Hukkam fi Usul al-'Aqdiyyah wa Manahij al-Ahkam. Beirut: Dar al-Kutub al-'Ilmiah.

Ibn Majah, Abu Abdillah Muhammad ibn Yazid Ibn Majah. 2008. Sunan Ibn Majah. Jilid 2. Beirut: Dar al-Kutub al-Ilmiah.

Jamal Sadiq al-Marsawi. 1984. Nidzam Al-Qada' fi al-Islam Idarah al-Thaqafah wa al-Nashr. Saudi Arabia: Jami'ah Imam Muhammad.

M. Mageswari. 2012. Syarie Lawyers Can Challenge His Suspension Order, Rules Judge. https:/www.thestar.com. my/news/nation/2012/10/13/syarie-lawyer-can-challengehis-suspension-order-rules-judge/ [13 Oktober 2019]

Mahmud Saedon A. Othman. 1996. Institusi Pentadbiran Undang-Undang dan Kehakiman Islam. Kuala Lumpur: Dewan Bahasa dan Pustaka. 
Masyhur Hassan Mahmud Sulayman. 1985. Al-Muhamah Tarikhuha fi al-Nazmi wa Mawwqif al-Syaria'ah alIslamiyyah Minha. Amman: Dar al-Fiha'.

Md Zawawi Abu Bakar. 2003. Isu-isu Peguam Syarie Di Malaysia. Jurnal Syariah Jilid 2.

Mohd Nadzri Bin Haji Abdul Rahman Ibrahim. 2010. UndangUndang Tatacara Mal Mahkamah Syariah: Prinsip dan Amalan. Cet. 4. Negeri Sembilan: Karya Kreatif Resources.

Muhamad Rauwwas Qal'aji, Hamid Saniq Qunaibi \& Kotob Mustafa Sanu. 1985. Mu'jam Lughat Al-Fuqaha'. Beirut: Dar al-Nafais

Muhammad bin Ismail bin Ibrahim bin al-Muqirah bin Bardizbah al-Bukhari. 2000. Sahih alBukhari, Mausuah alHadith al-Sharifal-Kutub al-Sittah. Riyad: Dar al-Salam li al-Nashr wa alTawzi. No. Hadith 2314,2315. Hlm 181.

Mujar Ibnu Syarif. 2010. Pengaduan Awam Menurut Perspektif Politik Islam. Kertas Kerja dibentangkan di Seminar Kebangsaan Pegurusan Aduan Awam Menurut Perspektif Islam anjuran Institut Perkembangan Minda (INMIND) dan Akademi Pengajian Islam, Universiti Malaya.27 Julai. Kuala Lumpur.

Musa Awang. 2017. http://www.iais.org.my/e/ attach/2017/29AUG2017/MusaAwang_ppt.pdf [21 Oktober 2019].

Musa, Awang. 2013. Peranan Peguam Syarie di Dalam Sistem Pentadbiran Kehakiman Islam di Malaysia: Sejarah, Cabaran dan Halatuju. Seminar Amalan Guaman Syarie 2013, 26 Oktober 2013. Klana Beach Resort Port Dickson.

Siti Zalikhah Hj. Md Noor. 2001. Kod Etika Peguam Syarie. Jurnal Hukum. Jilid 14. Bhg. 2.

Syeikh Abdullah ibn Sa'id Muhammad 'Abbadi Allahji, 1989. Jilid 3. Idhah al-Qawaid al-Fiqhiyyah. Mekah: Al-Madras bil-Madrasah al-Shoulatiyyah.

Syeikh Ghazali Hj Abd. Rahman. 2010. Perkembangan, Pengukuhan dan Menaiktaraf Mahkamah Syariah di Malaysia. Kertas Kerja dibentangkan dalam Seminar Syariah dan Undang-undang. t.th. Universiti Sains Islam Malaysia (USIM).

Syeikh Ghazali Hj Abd. Rahman. 2011. Peranan Majlis Agama Islam Negeri Memartabat Sistem Perundangan dan Kehakiman Syariah di Malaysia. Kertas Kerja dibentangkan di Kongres Majlis Agama Islam Negeri Seluruh Malaysia Anjuran Jabatan Kemajuan Islam Malaysia. 26-27 September. Kuala Lumpur.

Syeikh Ghazali. 2019. Bicara Pasca RUU Akta Profesion Guaman Syarie. Seminar Anjuran Persatuan Guaman
Syarie Malaysia (PGSM) dan Fakulti Syariah dan Undangundang KUIS. 9 Ogos. Kajang.

Temu bual bersama Dato’ Abu Bakar Abdullah Kutty, Hakim Kanan Mahkamah Tinggi Syariah Kota Bharu, Kelantan di Jabatan Kehakiman Syariah Kelantan. 17 Disember 2018.

Temu bual bersama Dato' Sri Haji Abdul Rahman bin Md Yunos, Ketua Hakim Syarie Pahang di Jabatan Kehakiman Syariah Pahang. 24 April 2019.

Temu bual bersama Datuk Jasri@Nasip bin Mat Jakir, Ketua Hakim Syarie Sabah di Kota Kinabalu Sabah. 13 Mac 2019.

Temu bual bersama Tuan Muhammad Adib bin Husain, Ketua Hakim Syarie Selangor di Jabatan Kehakiman Syariah Selangor. 22 April 2019.

Zafir Al-Wasimi. 1978. Nizam al-Hukum fi al-Syari'ah wa alTarikh al-Islamiy. Cetakan 1, Beirut: Dar al-Nafa'is.

Zafir Al-Wasimi. 1978. Nizam al-Hukum fi al-Syari'ah wa alTarikh al-Islamiy. Cet.1. Beirut: Dar al-Nafa'is.

Zulkifli Hasan. 2017. Ke Arah Penubuhan Badan Peguam Syarie. http://www.zulkiflihasan.com/wp-content/ uploads/2008/05/KE-ARAH-PENUBUHAN-BADANPEGUAM-SYARIE.pdf. Diakses pada: 21 Oktober 2019.

Hammad Mohamad Dahalan

Fakulti Syariah dan Undang-undang

Kolej Universiti Islam Antarabangsa Selangor

Kajang, Selangor.

E-mel:hammad@kuis.edu.my

Mas Nooraini Hj Mohiddin

Fakulti Syariah dan Undang-undang

Universiti Islam Sharif Ali

Brunei Darussalam.

Emel:masnooraini.mohiddin@unissa.edu.bn

Mohamad Rizal Abd Rahman

Fakulti Undang-undang

Universiti Kebangsaan Malaysia (UKM)

43600 UKM Bangi, Selangor

E-mel:noryn@ukm.edu.my

Nur Khalidah Dahlan

Fakulti Undang-undang

Universiti Kebangsaan Malaysia (UKM)

43600 UKM Bangi, Selangor

E-mel:nurkhalidahdahlan@ukm.edu.my 
